\section{Bioethics: Its Scope and Purpose}

\author{
Michael W. Fox \\ The Humane Society \\ of the United States
}

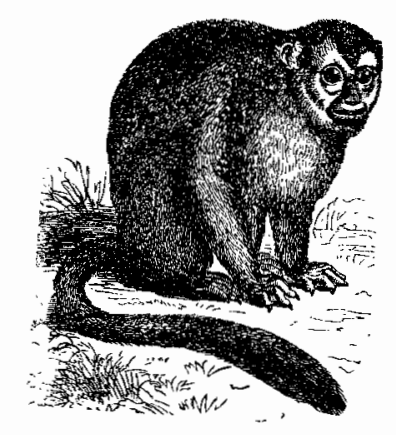

Bioethics is a term that is becoming widely used today. It entails the objective appraisal of how our values, desires and actions affect others, including animals and the environment. We have medical bioethics, which focuses on such ethical issues as euthanasia, surrogate parenting and genetic engineering involving human beings. Such bioethical issues have been deliberated by the World Council of Churches, among other groups. Increasingly these groups are beginning to apply bioethics in addressing and seeking remedies for a host of other social and environmental issues.

A healthy humanity is concerned about its humanity-how compassionately it acts toward its own kind and toward other sentient beings and the Earth itself. It has respect for all life because it realizes that when it damages the environment, it harms itself. Bioethics, in this regard, is a field of self investigation and enlightened self-interest. And it provides a foundation to establish meaning in our lives.

Bioethics offers a holistic, rational appraisal of our place in the world and how best we can live for the good of the life community of the planet. It mandates that equal and fair consideration be given to human

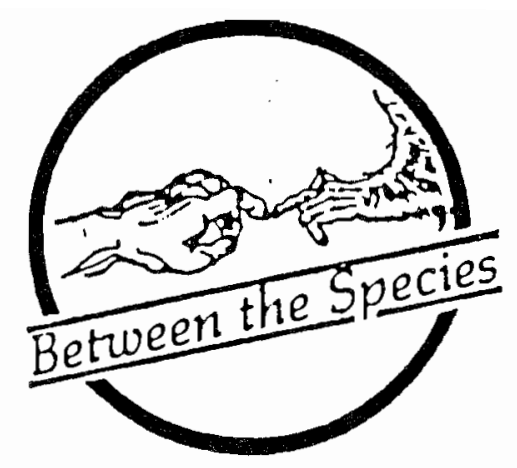

rights issues, animal rights issues, and environmental concerns. It includes a temporal principle of transgenerational equity - of being concerned about the well-being of future generations and having a respectful understanding of the wisdom and folly of our ancestors. We should neither forget our history, lest we repeat it, nor forget that "we do not own the land, we borrow it from our children."

The polemicized rhetoric and bickerings within and among frustrated factions of the human, animal, and environmental rights movements are reconciled by the integrative approach that applied bioethics provides.

Bioethics can be an antidote to the prevailing dominionistic attitude toward life. The subjugation of minorities and other life communities will continue as will war and other forms of violence until we reverse the belief that we are superior and apart from nature. ${ }^{1}$

Within what some call the "establishment"meaning the government-industrial complex-bioethics is also taking root. Ethical conduct, ethical advertising, ethical products, full cost-accounting (social and environmental) are beginning to appear on its agenda. Protection of endangered species; humane treatment of domestic animals; sustainable use of agricultural and other natural resources; loss of biodiversity; global warming, air pollution; national economic security; and industrial-economic sustainability; these and other issues fall within the sphere of bioethics.

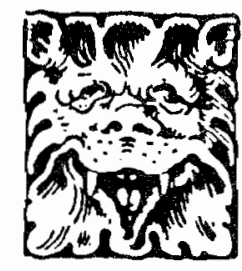


In this regard, bioethics can help lead policy makers and corporations toward a more holistic approach to clarifying and achieving their various goals, and in finding the most equitable and ethical means to achieve their desired ends. Ultimately, bioethics helps establish a common ground for all the different values and desires we all have. Different voices are heard-those who speak for the sick and dying, and those who speak for laboratory animals; those who speak for jobs and logs, and those who speak for spotted owls and sacred forests, or native peoples and cultural as well as biological diversity.

Bioethics is clearly a philosophic integration of human, animal and environmental rights. It fosters an Earth or Creation-centered world view, a "paradigm shift"-what E. F. Schumacher, the father of ecologicaleconomics (eco-nomics) termed "metanoia." Bioethics also helps establish a common ground for different views, the democratic process being facilitated by the principle of giving equal and fair consideration to all sides or aspects of a given issue concerning human, animal or environmental rights.

Decisions and full-cost accountings based upon bioethics should include scientific, economic, legal, moral, social, and environmental and compassionate considerations. They are not purely "science based" as is the trend today in such matters as wildlife protection, habitat conservation, FDA approval of geneticallyengineered bovine growth hormone and USDA approval of the release of genetically-engineered organisms into the environment.

The moral component of bioethics plays a central role. It is based on the principle of ahimsa - of avoiding $\mathrm{harm} / \mathrm{injury}$ in the process of furthering human interests and the good of society.

Whatever the issue, bioethics begins with the premise that all living beings and natural processes have purpose, if not interests. The derivative or inferred intrinsic value of other sentient beings and the inherent worth each being has in relation to its community are therefore acknowledged as deserving moral consideration.

The instrumental or extrinsic value of a given life form may appear insignificant, when we make our value judgment of its entire being on the basis of its degree of sentience or intelligence. Such judgment is invariably wrong. Without lowly fungi ${ }^{2}$ in the soil, for example, our crops and forests will be sickly, grow poorly and we suffer the consequences. We should, therefore, be mindful "of the least of these," and not continue to destroy them directly with agricultural chemicals and indirectly with industrial pollution, most notably acid rain.

Every community-human and nonhuman-also has intrinsic value, not only value to its members (in terms of security, continuation, etc.) but also to the larger life community of the planet's homeostatic and regenerative biospheric ecosystem. As Aldo Leopold wrote in his seminal book $A$ Sand County Almanac, "A thing is right when it tends to preserve the integrity, stability and beauty of the biotic community. It is wrong when it tends otherwise." And, as philosopher Ralph W. Gerard opined, "If nature is found to be a world of interdependence, then man is obliged to consider that characteristic as a moral dictum."

Actions and products that disrupt others' lives and/ or these life processes (which make up our life-support system) cannot be accurately forecast by the scientific method alone. When our thinking is in a linear mode, we focus too narrowly on the goal or gain, and not more broadly in terms of what means we utilize and to what ends; and what the long-term environmental, social and other consequences-risks and benefits-might be. Bioethics demands that we pay attention to these various means and consequences, and how our means and ends might violate the principle of ahimsa. We are, for the sake of our humanity —our dignity and integritybound to avoid causing harm or injury to any sentient being or to the biospheric ecosystem, when such harm or injury can be avoided. The all encompassing scope of bioethics allows for a higher degree of risk predictability. This is because bioethics operates from the moral principle of respect for all life. This means we must all strive to live non-violently, because when we directly or indirectly harm or injure sentient beings or the environment, we not only ultimately harm ourselves but demean and impoverish ourselves and the Earth in the process.

Bioethics posits that all life has been created by forces we do not yet fully comprehend; and that life is only ours in sacred trust. One of the founders of bioethics, Albert Schweitzer, ${ }^{3}$ wrote: "Ethics is in its unqualified form, extended responsibility with regard to everything that has life." $\mathrm{He}$ is unequivocal about the sense of duty that bioethics instills, stating that, "the universal ethic of reverence for life shows the sympathy with animals, which is so often represented as sentimentality, to be a duty that no man can escape." 
In a highly pragmatic sense, bioethics teaches us that when we take care of the earth, the earth will feed us; and that when we live in harmony with Nature, Nature will take care of us.

In conclusion, bioethics provides the necessarily holistic framework to help us deal more effectively with a host of issues that we face in our personal and professional lives. It enhances dialog and facilitates conflict resolution, and because of its democratic process, provides a firm foundation for a just and humane society.

\section{Bioethics: A Synopsis}

Bioethics literally means life ethics, the ethics by which we choose to live and relate to the life community of the Earth. It is a holistic philosophy, giving equal and fair consideration to the concerns, interests and rights of humankind, animalkind and the environment. It provides an objective as well as a compassionate and empathetic basis for how we choose to live as individuals, and as a society in terms of public policy, corporate responsibility and professional integrity.

Bioethics embraces two principles:

1. ahimsa (the avoidance of causing harm), and

2. transgenerational equity (concern for future generations).

It broadens the scope of responsibilities by incorporating concern for indigenous peoples, minorities, the environment or natural world, and animals wild and domesticated.

The health and sustainable economy triad depicted in Fig. 1 illustrates clearly how bioethics relates to the well-being of people, animals and nature.

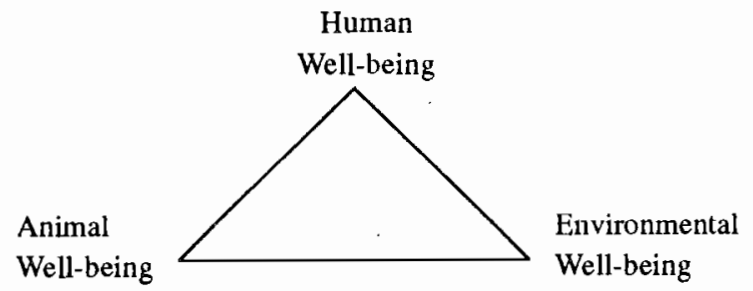

Health and Sustainable Economy Triad

Fig. 1
These ecological and ethico-spiritual connections reflect the interdependence of our life support systems and sustainable biotic communities. That we have fabricated non-sustainable bio-industrial economies and communities is evidenced by the possibly irreparable and irreversible environmental harm that we have caused, as well as suffering and extinction in the animal kingdom, and a world community neither free from pestilence nor war and want.

\section{Notes}

\footnotetext{
${ }^{1}$ See Jim Mason (1993) An Unnatural Order: Uncovering the Roots of Our Domination of Nature and Each Other. New York: Simon and Schuster.

${ }^{2}$ See Underground allies of plants. USDA's Agricultural Research, November 1989, pp. 10-13.

${ }^{3}$ See Albert Schweitzer (1947) Albert Schweitzer An Anthology. New York: Harper \& Bros.
}

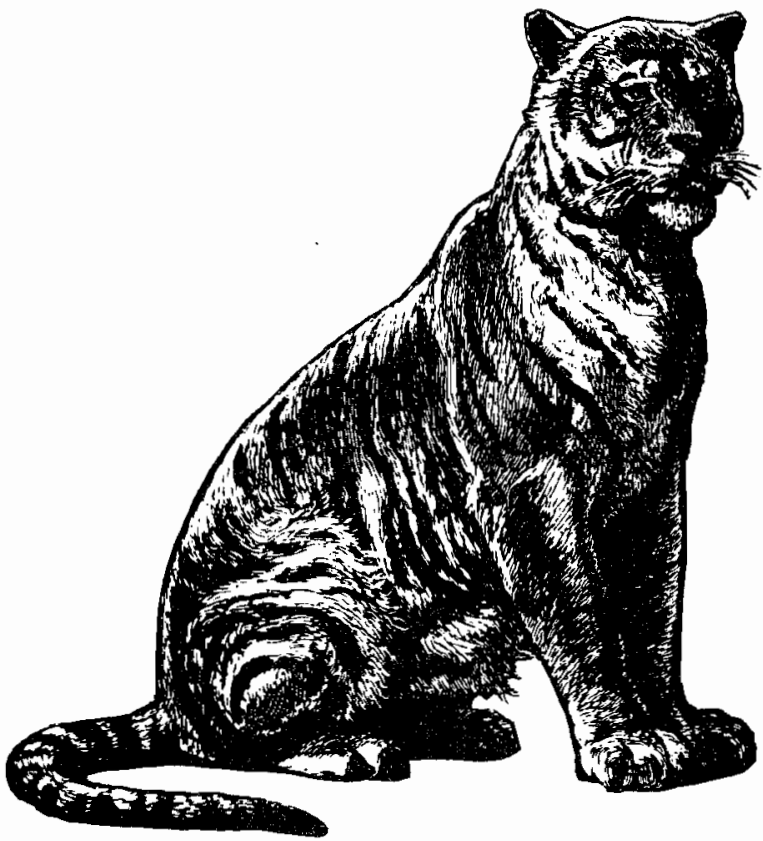

